\title{
Transformación en Archivos: un recorrido de la tecnología tradicional a la tecnología digital
}

\author{
Transformation in Archives: a journey from \\ traditional technology to digital technology
}

\author{
Isabel $\mathbf{M}^{\mathrm{a}}$ Sanz Caballero \\ isancab@gmail.com \\ Técnico de Archivo en Junta de Extremadura \\ Doctora en Documentación por la Universidad de Extremadura
}

\section{Resumen}

La aparición de las nuevas tecnologías ha supuesto una importante transformación. Los archivos no han quedado al margen y esta evolución del modelo tradicional al modelo digital, ha propiciado el surgimiento de nuevos conceptos como: documento electrónico, expediente electrónico o archivo electrónico, acordes a la era digital en la que nos encontramos. La implantación de la digitalización y la automatización de procesos y servicios en archivos ha acercado su contenido al usuario facilitando el acceso a los fondos, además este hecho ha garantizado la conservación de los mismos.

La presencia de los archivos en las redes sociales, así como las actividades de difusión de carácter virtual (exposiciones o visitas virtuales), accesibles a través de las webs de archivos, han supuesto también un mayor acercamiento de los archivos a la sociedad.

A pesar de las transformaciones surgidas y la apuesta por el modelo electrónico, queda aún un largo camino que recorrer para llegar a la transformación digital completa en archivos. En la actualidad, encontramos dos situaciones en los archivos: por un lado la coexistencia del modelo tradicional y digital, y por otro lado archivos con un modelo tradicional.

\section{Palabras clave}

Transformación digital, Archivo Electrónico, Documento Electrónico, Digitalización, Automatización.

\section{Abstract}

The appearance of new technologies has been an important transformation. Archives have not been left out and this evolution from the traditional model to the 
digital ones has led to the appearance of new concepts such as: "electronic document", "electronic archives" or "electronic filing", agreeing the digital era in which we live. The implementation of the digitizing and automation of processes and services in archives, has brought its content to the user facilitating the access to the fonds. In addition, this fact has guaranteed the conservation of the documents. The presence of archives in social networks, as well as the activities of virtual dissemination (virtual exhibitions or virtual visits), accessible through the archival websites, have also meant a closer approach of the archives to society.

In spite of the transformations that have arisen and the commitment to the electronic model, there is still a long way to go in order to achieve complete digital transformation in archives. Currently, there are two situations in archives: on the one hand the coexistence of traditional and digital model, and on the other hand archives with a traditional model.

\section{Keywords}

Digital Transformation, Electronic Archives, Electronic Documentation, Digitization, Automation.

Recibido: 26/03/2017

Aceptado: 19/05/2017

DOI: http://dx.doi.org/10.5557/IIMEI8-N14-043065

Descripción propuesta: SANZ CABALLERO, Isabel Ma., 2017. Transformación en Archivos: un recorrido de la tecnología tradicional a la tecnología digital. Métodos de Información, 8(14), pp. 43-65

\section{Introducción}

El mundo de los archivos está en constante evolución, el uso de las nuevas tecnologías ha traído consigo una mejora y renovación en las tareas propias de gestión documental.

La llamada Industria 4.0, denominada también como "Cuarta Revolución Industrial" ha supuesto un cambio de la tecnología tradicional a la tecnología digital que en buena medida ha implicado un buen grado de automatización de procesos. 
Casalet (1998), señala que dos de los factores fundamentales para resolver problemas de una sociedad dada son, por un lado el conjunto de conocimientos sobre la realidad que maneja esa sociedad en la solución de sus problemas y, por otro, el conjunto de maneras de hacer cosas para transformar esa realidad y resolver los problemas planteados y que incluyen los conocimientos necesarios para saber hacer, de estos dos conjuntos de saberes, surge la tecnología como el conjunto de conocimientos específicos y procesos para transformar la realidad y resolver algún problema.

La tecnología tradicional, ha dado paso a la tecnología digital, la transformación digital surge por tanto gracias a la aparición de las tecnologías. Stolterman y Croon (2004), definen transformación digital como "el cambio asociado con la aplicación de tecnología digital en todos los aspectos de sociedad humana".

La transformación digital puede ser considerada una de las etapas surgidas tras la adopción de tecnologías digitales. La etapa de transformación significa que los usos digitales permiten nuevos tipos de innovación y creatividad en un ámbito particular, más que sencillamente mejorar y apoyar los métodos tradicionales. La transformación digital en el ámbito de las organizaciones puede relacionarse directamente con el concepto de "eliminar el papel". Los archivos, como custodios de documentos en papel, no han pasado desapercibidos a estas transformaciones.

En los últimos tiempos se ha logrado la digitalización de un gran número de documentos que se encuentran en archivos, esto ha permitido mayor acceso de los usuarios a los fondos documentales, facilitado así, tareas como el préstamo o consulta de documentos en línea que además de evitar desplazamientos físicos al archivo, han garantizado la conservación de los mismos, aún así, actualmente, encontramos contextos de diferente grado de preparación, el Manual de documentos electrónicos del Consejo Internacional de Archivos (ICA) (2005), identifica tres contextos que suelen encontrarse los archiveros:

- archivos de reciente creación

- archivos ya establecidos que no han comenzado a trabajar con documentos electrónicos 
- archivos con un programa incipiente de documentos electrónicos que tiene que desarrollarse.

Si bien es cierto, que cada vez más proliferan los servicios en línea, que facilitan información y ofrecen la posibilidad de acceder a los documentos (Medrano y Suárez, 2005).

A consecuencia de esta revolución que ha supuesto una evolución de la tecnología tradicional en digital, han surgido en la Archivística nuevos conceptos como:

- documento electrónico

- expediente electrónico

- archivo electrónico

En la Figura 1, a continuación, se muestran de menor a mayor grado estos conceptos surgidos a consecuencia de la modernización de archivos. Podemos denominar archivo electrónico al sistema que facilita el almacenamiento de los documentos electrónicos que forman parte de un expediente electrónico, generado en el ejercicio de las actividades administrativas.

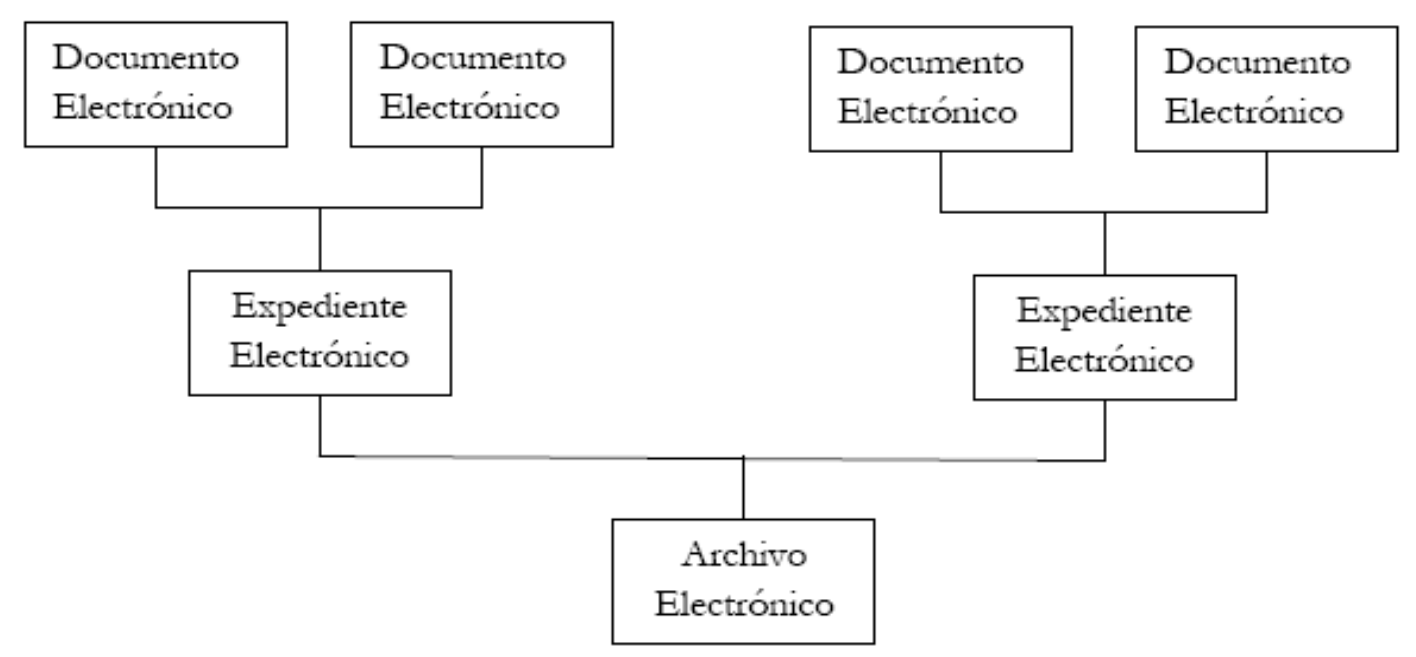

Figura 1. Archivo electrónico, expediente electrónico y documento electrónico

Según el Portal de Administración Electrónica (PAe) estos archivos electrónicos, están destinados a cubrir el conjunto del ciclo de vida de los documentos electrónicos y vienen a ser complementarios y equivalentes a los archivos convencionales. 
Como puede observarse en esta definición ofrecida por el Portal de Administración Electrónica (PAe), aún no existe ruptura total entre el archivo tradicional y el electrónico considerándose a este último como un elemento complementario al tradicional.

\section{Conceptos fundamentales: documento electrónico, expediente electrónico y archivo electrónico}

La Ley 59/2003, de 19 de diciembre, de firma electrónica denomina documento electrónico a la "información de cualquier naturaleza en forma electrónica, archivada en un soporte electrónico según un formato determinado y susceptible de identificación y tratamiento diferenciado”.

Cruz (2011), ofrece dos acepciones de documento electrónico, la primera de ellas: lo define como "documento generado, gestionado, conservado y transmitido por medios electrónicos, informáticos o telemáticos, siempre que incorporen datos firmados electrónicamente", y la segunda acepción que ofrece es: "la información de cualquier naturaleza en forma electrónica, archivada en un soporte electrónico según un formato determinado $y$ susceptible de identificación y tratamiento diferenciado" (Ley 56/2007, de 28 de diciembre, de Medidas de Impulso de la Sociedad de la Información).

Según Marcos (1999), cada vez más, los documentos electrónicos integran mayor parte de los recursos de información de las organizaciones. Por eso es muy importante que se diseñe un buen sistema de gestión de documentos que soporte las necesidades de la organización y sea capaz al mismo tiempo de proveer la información requerida rápida y eficazmente, y de proteger los datos almacenados en el sistema. Se pueden establecer tres características que deben cumplir los documentos en ese sistema:

- Ser accesibles y estar disponibles con facilidad, pero manteniendo la seguridad en el almacenamiento.

- Ser manejables para que sirvan de base a la creación de nuevos documentos.

- Ser precisos y exactos. Es importante que se pueda distinguir entre distintas versiones para que los usuarios tomen decisiones basadas en información precisa. 
Según Esteban (2001), no hay que olvidar la necesidad de contar con una aplicación informática que ayude a la gestión de los documentos electrónicos, la cual puede ser el mismo sistema de gestión electrónica de archivos que se utiliza para informatizar las actividades que se realizan en los archivos sin documentos digitales, sin embargo, la tendencia actual se dirige al desarrollo de sistemas integrados de gestión de la información, que sirven tanto para la producción de datos y documentos como para la gestión documental.

Con respecto al expediente electrónico, concepto definido en la Ley 11/2007, de 22 de junio, de acceso electrónico de los ciudadanos a los servicios públicos, el expediente electrónico es "el conjunto de documentos electrónicos correspondientes a un procedimiento administrativo, cualquiera que sea el tipo de información que contengan”. El foliado de los expedientes electrónicos se lleva a cabo mediante un índice electrónico, firmado por la Administración, órgano o entidad actuante, según proceda. Este índice garantiza la integridad del expediente electrónico y permite su recuperación siempre que sea preciso, siendo admisible que un mismo documento forme parte de distintos expedientes electrónicos. La remisión de expedientes podrá ser sustituida a todos los efectos legales por la puesta a disposición del expediente electrónico, teniendo el interesado derecho a obtener copia del mismo.

En cuanto al concepto de archivo electrónico, Cerdá (2002), ya señalaba las estrategias a seguir para crear un sistema de acceso telemático a los fondos documentales de un archivo, un entorno que ha recibido muy diversas acepciones: "archivo electrónico", “archivo virtual” o "archivo digital”.

- Archivo virtual: sistema de gestión de documentos, archivos o fondos de archivo que se hacen accesibles a través de la web, sin que necesariamente tengan como referencia un centro o sistema de archivos. Es un archivo "ex novo", creado por y para la red, o editados electrónicamente. Gracias a la facilidad de edición, comunicación y reproducción de los nuevos soportes se agrupan "virtualmente" documentos sobre determinado tema, persona, territorio o periodo cronológico. Son los archivos donde mejor se puede aplicar la "desmaterialización" del documento y del archivo tradicional. 
- Archivo digital: sistema de gestión de documentos basado en la captura y procesamiento de imágenes digitales, creadas a partir de cualquiera de los dispositivos existentes (escáner o cámara digital), desde su soporte original (papel, microfilm, negativos, diapositivas, placas de cristal, etc...), y dirigido a su posterior implementación en un sistema de búsqueda y recuperación donde quedan asociadas las imágenes digitales con la descripción de los documentos.

- Archivo electrónico: sistema de gestión de documentos que lleva implícito en su tratamiento y recuperación un medio electrónico o informático, en cualquiera de sus variantes. Tienen cabida tanto imágenes digitales como otro tipo de documentos, particularmente los que utilizan el formato de caracteres ASCII, después de someter un fichero digital a OCR1, documentos directamente elaborados en un procesador de textos o editados en HTML, SGML, XML, o tecnologías específicas como el sistema COLD2. Es por tanto un concepto más global y más adecuado para definir las múltiples posibilidades y variables de este nuevo entorno tecnológico.

Cruz (2011), define archivo electrónico a aquel que "está integrado por documentos y expedientes creados, recibidos, utilizados y conservados por medios electrónicos por una persona física o jurídica en el desarrollo de sus actividades, y que se mantienen accesibles por tales medios; entre los que se consideran incluidos las copias o reproducciones electrónicas de originales de otro tipo".

Otra definición de archivo electrónico es la ofrecida por Esteban (2001), que lo define como "el conjunto de documentos producidos, recibidos o reunidos por una persona física o jurídica de modo involuntario, natural y espontáneo en el transcurso, y como apoyo, de su actividad de la que es testimonio, haciendo uso de la electrónica, que se conservan y transmiten también mediante medios electrónicos en depósitos de conservación permanente tras efectuar una selección a partir de la identificación y valoración de las series, con medidas de autentificación y de preservación adecuadas y con una organización respetuosa con su modo de producción, con el fin de garantizar su valor informativo, legal y cultural así como de permitir su acceso y uso también mediante las tecnologías de la información”. 
La Ley 11/2007, de 22 de junio, de acceso electrónico de los ciudadanos a los servicios públicos, ofrece una serie de indicaciones para tener en cuenta con respecto al archivo electrónico de documentos:

- Podrán almacenarse por medios electrónicos todos los documentos utilizados en las actuaciones administrativas.

- Los documentos electrónicos que contengan actos administrativos que afecten a derechos o intereses de los particulares deberán conservarse en soportes de esta naturaleza, ya sea en el mismo formato a partir del que se originó el documento o en otro cualquiera que asegure la identidad e integridad de la información necesaria para reproducirlo. Se asegurará en todo caso la posibilidad de trasladar los datos a otros formatos y soportes que garanticen el acceso desde diferentes aplicaciones.

- Los medios o soportes en que se almacenen documentos, deberán contar con medidas de seguridad que garanticen la integridad, autenticidad, confidencialidad, calidad, protección y conservación de los documentos almacenados. En particular, asegurarán la identificación de los usuarios y el control de accesos, así como el cumplimiento de las garantías previstas en la legislación de protección de datos.

La Ley 39/2015, de 1 de octubre, del Procedimiento Administrativo Común de las Administraciones Públicas, de reciente entrada en vigor, indica que:

- Cada Administración deberá mantener un archivo electrónico único de los documentos electrónicos que correspondan a procedimientos finalizados, en los términos establecidos en la normativa reguladora aplicable.

- Los documentos electrónicos deberán conservarse en un formato que permita garantizar la autenticidad, integridad y conservación del documento, así como su consulta con independencia del tiempo transcurrido desde su emisión. Se asegurará en todo caso la posibilidad de trasladar los datos a otros formatos y soportes que garanticen el acceso desde diferentes aplicaciones. La eliminación de dichos documentos deberá ser autorizada de acuerdo a lo dispuesto en la normativa aplicable. 
- Los medios o soportes en que se almacenen documentos, deberán contar con medidas de seguridad, de acuerdo con lo previsto en el Esquema Nacional de Seguridad, que garanticen la integridad, autenticidad, confidencialidad, calidad, protección y conservación de los documentos almacenados. En particular, asegurarán la identificación de los usuarios y el control de accesos, así como el cumplimiento de las garantías previstas en la legislación de protección de datos.

\section{Digitalización de documentos}

Como hemos comentado con anterioridad, la digitalización de archivos ha supuesto una importante evolución en cuanto a las tareas archivísticas se refiere, la digitalización de archivos entre otros procesos como el tratamiento automático de datos, también denominado como automatización y definido en el Diccionario de Terminología Archivística (1995) cómo las "operaciones informáticas ejecutadas con equipos mecánicos o electrónicos que permiten la rápida utilización de grandes cantidades de información para agilizar la gestión y tratamiento de los archivos", está permitiendo facilitar el acceso a fondos, además de lograr una mayor conservación y control de documentos.

Heredia (2011), define digitalización como el "proceso metodológico que permite convertir un documento en soporte papel o en otro soporte no electrónico en uno o varios ficheros electrónicos que contienen la imagen codificada, fiel e íntegra del documento", además, destaca que la digitalización es la manifestación actualizada de la reproducción y es también la manifestación actual de la última etapa de la gestión documental que no es otra que la difusión y el servicio de los documentos, se planifica con fines de conservación y no puede confundirse con la gestión documental electrónica, ni con normalización aunque tenga que ver con una y otra.

Existen diversos manuales sobre recomendaciones para la conversión de documento tradicional a digital, a continuación, se muestra la guía de diez pasos elaborada en 2005 por el grupo de expertos de IFLA e ICA (International Council on Archives) invitados a elaborarlas por la UNESCO para asegurar un buen proceso de conversión:

1. Utilice escáneres que puedan adecuarse a: 
a. las dimensiones físicas de los documentos originales

b. el tipo de soporte implicado (transparente o reflectante)

c. el nivel de los detalles, tonos y colores presentes en los documentos

d. el estado físico de los documentos.

2. Examine cuidadosamente si existe algún requisito para una manipulación concreta o de conservación de los documentos originales antes de escanearlos.

3. Elija una resolución que sea suficiente para capturar los más sutiles detalles requeridos por el grupo de documentos originales que se van a escanear. Compruebe que la resolución no limitará el uso que se pretende conseguir para las imágenes digitales. Establezca la resolución en el nivel elegido para todo el grupo de documentos originales con el objetivo de evitar la revisión de documento por documento.

4. Elija una profundidad de bit que esté en consonancia con las características de los documentos originales y con el nivel necesario para transferir el contenido informativo: escaneo binario para documentos textuales que consistan en imágenes en negro sobre papel blanco; escaneo en escala de grises (8 bits) para documentos que contengan información significativa en escala de grises (incluidas las anotaciones a lápiz en el texto) y para materiales fotográficos; escaneo en color para documentos que contengan información en color, especialmente cuando se necesiten copias facsímiles de gran calidad.

5. Utilice los procedimientos de optimización de las imágenes y los documentos cuidadosamente siempre que este tipo de procesos se lleven a cabo.

6. Utilice las técnicas de compresión normalizadas "sin pérdida" para los ficheros de conservación y seguridad (maestros) y para los ficheros de acceso cuando sea necesario. Esto significa, por ejemplo:

a. para la compresión: ITU grupo 3 o 4 y JBIG (imágenes binarias), JPEG/JPEG 2000 or LZW (imágenes multi-bit) sin pérdida

b. para el intercambio: JPEG/JPEG 2000 sin pérdida, TIFF 5 o versiones superiores

7. Lleve a cabo cuidadosamente ensayos de acceso a los ficheros con el fin de encontrar un equilibrio entre una calidad visual aceptable para el usuario y el tamaño del fichero de modo que el ordenador pueda acceder al mismo en un tiempo aceptable. 
8. Para obtener un buen rendimiento de los equipos utilizados, investigue cuidadosamente las declaraciones de los fabricantes acerca de las potencialidades del sistema y confírmelas mediante pruebas y referencias.

9. Utilice estándares para la evaluación de calidad de la imagen digital.

10. Desarrolle un programa continuo de control de calidad para verificar la consistencia de la producción de los distintos técnicos durante el proceso del escaneo.

El formato electrónico facilita el acceso y la transmisión de la información, permite el tratamiento de la imagen ofreciendo distintas posibilidades de visualización y la reproducción sin dañar el original. Las barreras físicas o temporales desaparecen en el caso de los datos incorporados a la Red. Sin embargo, la esperanza de vida de estos materiales es muy corta, requiriendo un seguimiento constante y la actualización continuada de los datos (Argerich, 2010).

El Manual de documentos electrónicos del Consejo Internacional de Archivos (ICA) (2005), realiza una descripción de los sistemas electrónicos de archivo. En las organizaciones que producen y gestionan documentos se utilizan diferentes tipos de sistemas ofimáticos, estos sistemas pueden estar enfocados hacia la recuperación de información (por ejemplo, los sistemas de gestión de documentos de apoyo informativo) o hacia el apoyo a los procesos de trabajo de una organización (por ejemplo, los sistemas de flujo de trabajo). Los sistemas electrónicos de archivo también pueden incluir sistemas autónomos o que no estén en red. Sin embargo, en el contexto de una oficina moderna, esos sistemas suelen estar integrados en entornos de red repartidos en diferentes niveles. Se puede partir de un entorno cliente-servidor independiente en una organización, en el cual se compartan aplicaciones y servicios mediante estaciones de trabajo descentralizadas; seguir con la integración de esta red en un entorno de Intranet en la que puedan participar varias organizaciones (por ejemplo, varios departamentos gubernamentales), $y$ terminar con una red de información basada en Internet. En lugar de constituir diferentes etapas, los tres niveles de sistemas de red, descentralizados e independientes, pueden existir de manera simultánea y gestionar información con diferentes grados de confidencialidad y seguridad en entornos de red diferentes. 
Los sistemas de archivo garantizan el mantenimiento y la conservación de la autenticidad, fiabilidad y accesibilidad de los documentos a lo largo del tiempo. Para que los sistemas cumplan estos requisitos será necesario implementar las funciones archivísticas adecuadas a lo largo del ciclo de vida de los documentos.

En el Real Decreto 4/2010, de 8 de enero, por el que se regula el Esquema Nacional de Interoperabilidad en el ámbito de la administración electrónica, se define digitalización como el "proceso tecnológico que permite convertir un documento en soporte papel o en otro soporte no electrónico en uno o varios ficheros electrónicos que contienen la imagen codificada, fiel e íntegra del documento".

La digitalización representa, un método y un reto para la conservación.

La digitalización de documentos en soporte papel por parte de las administraciones públicas se realiza de acuerdo con lo indicado en la norma técnica de interoperabilidad correspondiente en relación con los siguientes aspectos:

a) Formatos estándares de uso común para la digitalización de documentos en soporte papel y técnica de compresión empleada, de acuerdo con lo previsto en el artículo 11.

b) Nivel de resolución.

c) Garantía de imagen fiel e íntegra.

d) Metadatos mínimos obligatorios y complementarios, asociados al proceso de digitalización.

Según se recoge en esta norma técnica, la gestión y conservación del documento electrónico digitalizado atiende la posible existencia del mismo en otro soporte.

Como puede observarse, no se aprecia ruptura entre archivo tradicional y archivo digital, sino que se apunta a la convivencia del documento electrónico y el documento físico. La digitalización de documentos, así como el hecho de contar con un archivo electrónico, ha traído consigo una serie de ventajas entre las que se encuentra facilitar el acceso al documento y propiciar un sistema de préstamo automatizado como herramienta de acceso a fondos. 


\section{E1 servicio de referencia digital}

El servicio de consulta y referencia es el responsable de posibilitar el acceso a la información de quien la necesite, en el momento y en la forma precisa (Sánchez, 2003).

La mayoría de los autores están de acuerdo en que el servicio de referencia virtual está basado más en la forma que en el fondo, es decir, que toda la transacción de referencia es llevada a cabo de modo virtual siguiendo la máxima de Taylor "en cualquier sitio, espacio, a cualquier ritmo y en cualquier momento". Aquí radica lo novedoso de este servicio: se ofrece total libertad de acceso al mismo (García, 2004).

Lankes (2000) identifica cinco componentes fundamentales en los servicios de referencia digital:

- Recepción por vía electrónica de la pregunta.

- Envío al especialista, puede que la pregunta pase a una cola de espera de acuerdo con los criterios marcados por el servicio.

- Composición de la respuesta de acuerdo con la política del servicio.

- Envío de la respuesta.

- Seguimiento e identificación de los temas más demandados para estadísticas y generación de archivos.

En cuanto a los servicios de referencia en archivos, Bonilla (2001), destaca que: "existen numerosas carencias en el seno de la investigación sobre el trabajo de referencia desarrollado en los archivos, pero todas ellas no constituyen sino un importante campo de estudio así como futuros retos de los que se deriven consecuencias positivas y mejoras en la función informativa del archivo. Una vez admitido el papel fundamental que el servicio de referencia puede jugar en el entorno informativo y cultural del archivo, es preciso delimitar las áreas de trabajo en torno al trabajo de referencia. Por una parte, el análisis de los colectivos de usuarios así como la recogida, registro y tratamiento de los datos procedentes de las estrategias y modos desplegados para acceder a los documentos permiten disponer de un caudal informativo de gran valor para planificar las estrategias de actuación en el servicio de referencia. Por otra parte, se hace necesario incidir en los modos de acceso temático desarrollando para ello mecanismos e instrumentos de información que compaginen la teoría organizativa archivística con unas demandas 
documentales por materias. En este sentido, el archivero de referencia ocupa un lugar destacado de intermediario entre los fondos organizados según el principio de procedencia y unos requerimientos de los usuarios. Junto a ello, el conocimiento y la destreza en el manejo de cuantos recursos de información, formales e informales, ayuden a las necesidades del usuario, se contemplan como características propias del perfil profesional de referencia. Finalmente, la irrupción del entorno web en el servicio de referencia es considerada como la gran vía de trabajo futura, que permita dar respuesta a demandas de información de los usuarios de forma remota, contribuyendo, con la puesta a disposición del usuario de los instrumentos de descripción y ayuda, a una proximidad más efectiva y fructífera entre sociedad y archivo".

\section{Acceso automatizado a los fondos de archivos}

Si realizamos una búsqueda de información acerca de préstamo de documentos, encontraremos que el préstamo de tipo digital más extendido es el que se realiza en bibliotecas y que tiene como fin el préstamo de e-books, sin embargo, aunque existe escasa bibliografía sobre este tipo de préstamo en archivos, en los últimos tiempos, este servicio ha ido afianzándose también en archivos.

El Diccionario de Terminología Archivística, define préstamo de documentos a la "acción que implica la salida temporal de documentos de un archivo con fines administrativos o de difusión cultural".

El préstamo de documentos en archivos, supone una importante herramienta de control sobre los documentos, a través de él podemos comprobar la localización y la circulación de los expedientes de archivo.

El Manual de archivos de la Universidad de Alicante (2014), distingue entre dos tipos de préstamo:

- Préstamo interno: salida temporal de documentos originales del archivo hacia unidades administrativas que lo soliciten para:

a) Dar continuidad a la tramitación administrativa de dichas unidades, siempre que la necesidad exija disponer de los documentos originales y no pueda cubrirse con la consulta de los mismos en las instalaciones del archivo. 
- Préstamo externo: salida temporal de documentos originales del archivo fuera del ámbito de la institución, con la finalidad de:

a) Cumplir con los imperativos legales, cuando la documentación original es reclamada por la Administración de Justicia o por otros organismos públicos.

b) Colaborar en actividades culturales externas y difundir los fondos, cuando los documentos son prestados para la celebración de exposiciones

A menudo, el préstamo se realiza de forma manual mediante los siguientes pasos:

- Solicitud de préstamo: mediante un modelo diseñado previamente, la unidad administrativa, solicita los documentos al archivo de gestión u oficina

- Autorizaciones: el personal que solicita los documentos debe estar autorizado por el archivo con anterioridad en un fichero de autorizados.

- Procedimiento de préstamo: el archivero gestiona el préstamo localizando el expediente en su base de datos.

- Testigo: el archivero elabora tres documentos idénticos denominados testigos. Estos testigos recogerán los datos del expediente objeto de préstamo, así como los datos del solicitante de dicha petición.

1. Un testigo irá cogido a la solapa del expediente.

2. Otro testigo, quedará en la caja del expediente.

3. Y otro testigo se incluirá en un Registro de Salidas.

- Registro de salidas: en él se incluirán los testigos correspondientes a las salidas de expedientes del archivo.

- Registro de entradas: en él se incluirán los testigos de las devoluciones de los expedientes que han sido devueltos al archivo.

El concepto de préstamo tradicional ha cambiado en los últimos tiempos, introduciéndose el préstamo automatizado. La implantación de la digitalización documental en archivos ha supuesto como se ha comentado con anterioridad un importante progreso en cuanto al acceso y difusión de fondos mediante préstamo y consulta automatizada, lo que ha permitido facilitar la labor del usuario. Como ya señalaba Gil (1997), la digitalización ha permitido 
que el usuario acceda a la consulta directa o pueda seleccionar distintos listados como instrumentos de consulta por medio de servidor en la sala de investigadores o por medio de Internet (web y e-mail), este autor narraba la experiencia en el Archivo Municipal de Vila-real en el que la digitalización de documentos consultables online se empezó a desarrollar según iban llegando las peticiones de los usuarios, permitiendo que el archivo pudiera ofertar todos los pergaminos que conservaba (1245-1690) por Internet, y destacaba que "es necesario contar con unas bases comunes en la ejecución de nuestra profesión que adecuen los archivos a las nuevas necesidades que se esperan de nuestra práctica profesional. Solo así se logrará la tan cacareada aproximación entre Administración y administrado".

\section{Presencia de los archivos en la Red y difusión digital de fondos}

La Web 2.0 o Web Social, ha supuesto un hito importante de cara a la presencia de los archivos en la Red y al auge de las redes sociales.

Las páginas webs de los archivos se han convertido en un importante escaparate en el que se facilita el acceso a la información de forma clara y sencilla ofreciendo diferentes servicios a los usuarios, por otro lado, la presencia de los archivos en las redes sociales, ha supuesto una mayor visibilidad de sus funciones y una mayor interconexión entre profesionales y usuarios.

El Diccionario de la Real Academia Española, define red social como la "Plataforma digital de comunicación global que pone en contacto a gran número de usuarios", en los últimos tiempos, estar presente en la red social ha constituido una revolución y un adelanto que ha permitido mostrar la visibilidad de instituciones hasta entonces desconocidas como ha sido el caso de los archivos. Numerosos archivos poseen actualmente perfiles en redes sociales como Facebook o Twitter, además de poseer un gran número de seguidores que interactúan entre sí.

La aparición de la Web Semántica o Web Social ha traído consigo webs cuyas páginas se encuentran más organizadas, estructuradas y codificadas.

Según Acuña y Agenjo (2005), la web semántica tiene como objetivo "sustentar los sitios y servicios de la web en unas nuevas estructuras de información constituidas por una red organizada de conceptos y relaciones 
semánticas pertenecientes a un dominio del conocimiento a las que se denomina "ontologías". Para Acuña y Agenjo (2005) "hacer factible la visibilidad de los recursos digitales existentes y mejorar su búsqueda y recuperación se ha convertido en el objetivo fundamental de los organismos que, a escala internacional, están impulsando su desarrollo".

Las páginas webs, así como las redes sociales en archivos, han favorecido el acercamiento de las diferentes actividades de difusión que se llevan a cabo en los archivos. En los últimos tiempos muchas de ellas de carácter virtual, un ejemplo de ello son las exposiciones o visitas virtuales.

- Exposiciones virtuales: estar presente en Internet multiplica las posibilidades de difusión y conocimiento para atraer a un mayor número de público, a la vez que supone una reducción notable de los costos de organización y mantenimiento y de desplazamiento para los interesados. La diferencia fundamental entre uno y otro tipo de exposiciones radica en el modo de presencia de los objetos. Por otra parte, las exposiciones diseñadas en la red pueden superar los límites espaciales de las presenciales, circunstancia que dificulta y limita la posibilidad de visitarlas (Herrera, 2002).

Existen dos tipos de exposiciones: reales y virtuales (Jaén, 2006). Las virtuales son diseñadas para instalar en Internet, en el sitio web del archivo o bien en soportes digitales (CD o DVD). Sus ventajas son muchas: no requieren local, seguridad o vitrinas; son de bajo costo económico, interactivas, perduran en el tiempo y en el espacio y llegan a un público más amplio (Jaén, 2006).

- Visita o recorrido virtual: Ulldemolins (2013, pp. 9-25) define recorrido virtual como "una simulación de un lugar virtual compuesto por una secuencia de imágenes".

\section{Riesgos y autenticidad en ambientes digitales}

El cambio de la tecnología tradicional a la tecnología digital, ha traído consigo numerosas ventajas, pero también una serie de riesgos y costes que ha sido preciso asumir.

En cuanto a los riesgos, podemos destacamos los dos siguientes: 
- Riesgos en la autenticidad y fiabilidad de los documentos: Marcos (1999), señala como riesgo entre otros, la obsolescencia de los sistemas por el avance de la tecnología, además señala que el inconveniente del documento electrónico, es que puede dar lugar a manipulaciones, poniendo en duda su autenticidad y su fiabilidad, características fundamentales en la documentación de archivo, por ello, recomienda involucrar al archivo en el ciclo completo de vida de los documentos para cerciorarse de que mantienen la autenticidad y las condiciones de preservación desde su creación, y destaca que "una vez que el documento deja de ser utilizado de forma usual en la organización, la valoración es desaconsejable por muchos motivos. Si se hace en ese momento existe el riesgo de que los documentos previstos no hayan sido creados, o puede que no se pueda demostrar su autenticidad, o que lleguen incompletos o incomprensibles, o que no reflejen las actividades llevadas a cabo por la organización en el ejercicio de sus funciones, además, un cambio en el sistema previsto en esta última etapa imposibilitaría acceder a documentos antiguos o anularía su autenticidad al poder ser manipulados"

- Riesgos en la preservación digital:

En 2010, el grupo de trabajo ISO responsable de Digital Records Preservation, destacaba que el carácter singular de los documentos electrónicos originaba un número de desafíos que necesitaban ser abordados si los documentos debían de ser preservados a lo largo del tiempo. Estos desafíos a menudo se presentaban mucho antes de que el período de conservación de los documentos hubiera finalizado y señalaban los principales retos: a) la obsolescencia y degradación de los formatos físicos (soportes); b) la obsolescencia de los formatos de ficheros; c) la obsolescencia del software (sistemas operativos, etc); d) la obsolescencia del hardware.

a) Obsolescencia y degradación de los formatos físicos (soportes) Los documentos electrónicos se almacenan en soportes tecnológicos que están sujetos al deterioro y degradación por el paso del tiempo. El deterioro puede ser el resultado de condiciones de almacenamiento, procedimientos para el tratamiento o mantenimiento de equipos de lectura inapropiados. 
Asimismo, el rápido cambio de la tecnología de los soportes de almacenamiento normalmente conduce a la obsolescencia en períodos de tiempo relativamente cortos.

b) Obsolescencia de los formatos de ficheros

Agravando el reto de los soportes está el hecho de que los datos precisan ser representados utilizando programas de software. Estos programas sólo pueden leer e interpretar los datos con un formato de fichero específico. Los proveedores de software están actualizando continuamente sus sistemas para añadirles nuevas funcionalidades y esto supone un riesgo porque los antiguos formatos pueden no ser legibles por los nuevos sistemas de software.

c) Obsolescencia del software

En relación con los desafíos citados más arriba, está el hecho de que los propios programas de software se convierten en obsoletos, de ahí que el formato de fichero resulte inútil. La obsolescencia del software puede presentarse tanto en programas de aplicación como en los sistemas operativos sobre los cuales las aplicaciones corren. La obsolescencia de cualquiera de estas plataformas puede tener como resultado que los documentos no puedan visualizarse.

d) Obsolescencia del hardware

Aunque los soportes físicos estén todavía en buen estado, puede no existir en el futuro la tecnología para leer estos soportes. Al igual que en el reto del software, los nuevos avances en el hardware desarrollan rápidamente tecnologías más sólidas. De la misma forma que las tecnologías del hardware avanzan, la información que se almacena y recupera debe cambiar y no deben mantenerse soportes antiguos.

En cuanto a los costes, Cruz (2015) advierte la dificultad de evaluar los costes de la planificación de la preservación digital a largo plazo, pues los factores integrantes se mueven en el corto y medio plazo. No obstante, destaca que se puede manejar una estructura de gastos a base de elementos fijos, en tanto que están presentes siempre (Crespo y García Molina 2001; Unesco 2003):

1) La infraestructura tecnológica 
2) Los costes operativos no laborales: concepto que engloba todos los necesarios para mantener un repositorio de archivo digital, excluidos los laborales, como son: el espacio físico (edificio o local)y las instalaciones, el suministro eléctrico, el aire acondicionado, el mantenimiento y las reparaciones, las actualizaciones, etc.

3) Los costes laborales.

4) La adquisición de información.

5) Los derechos de autor.

6) Los seguros.

7) La no disponibilidad del repositorio por las causas que sea, como mantenimiento, reparación, etc.

8) Las pérdidas de datos, documentos y publicaciones.

9) Los costes de desarrollo o puesta en marcha del programa de preservación permanente.

10) Los costes inherentes a la actividad específica.

\section{Conclusiones}

- La transformación digital surge gracias a la aparición de las tecnologías y puede ser considerada una de las etapas surgidas tras la adopción de tecnologías digitales.

- El proceso de transformación digital en archivos está siendo muy largo, hasta el momento, en la mayoría de los casos, encontramos la coexistencia entre el modelo tradicional y el modelo digital, este último sigue implantándose tímidamente en muchos archivos.

- Es evidente que la aparición de las nuevas tecnologías, ha supuesto una importante transformación en los archivos, como son: la aparición de nuevos conceptos como: documento electrónico, expediente electrónico y archivo electrónico, nuevos procesos como son: la automatización y la digitalización o nuevas tareas como por ejemplo el préstamo automatizado de documentos o el servicio de referencia digital, la consulta on-line. etc.

- Los archivos electrónicos, están destinados a cubrir el conjunto del ciclo de vida de los documentos electrónicos y vienen a ser complementarios y equivalentes a los archivos convencionales.

- El concepto de préstamo tradicional ha cambiado en los últimos tiempos, introduciéndose el préstamo automatizado. La implantación 
de la digitalización documental en archivos ha supuesto como se ha comentado con anterioridad un importante progreso en cuanto al acceso y difusión de fondos mediante préstamo y consulta automatizada, lo que ha permitido facilitar la labor del usuario.

- La irrupción del entorno web en el servicio de referencia ha permitido dar respuesta a demandas de información de los usuarios de forma remota, colaborando, con la puesta a disposición del usuario de los instrumentos de descripción y ayuda, y contribuyendo a un acercamiento más efectivo y fructífero entre sociedad y archivo.

- Las páginas webs de los archivos se han convertido en un importante escaparate en el que se facilita el acceso a la información de forma clara y sencilla ofreciendo diferentes servicios a los usuarios.

- La presencia de los archivos en las redes sociales, así como las actividades de difusión de carácter virtual (exposiciones o visitas virtuales), accesibles a través de las webs de archivos, han posibilitado un mayor acercamiento de los archivos a la sociedad, sin embargo, queda aún un largo camino que recorrer para llegar a la transformación digital completa en archivos.

- En contraposición a todas las ventajas que ha supuesto el cambio de la tecnología tradicional a la tecnología digital, este ha traído consigo a su vez una serie de riesgos y costes derivados de la preservación digital permanente, necesarios de asumir para llevar a cabo esta transformación de forma eficaz.

\section{Bibliografía}

ARGERICH, Isabel, et al., 2010. Conservación preventiva y plan de gestión de desastres en archivos y bibliotecas. Madrid: Ministerio de Cultura, Subdirección General de Publicaciones, Información y Documentación.

BONILLA, Diego Navarro, 2001. El servicio de referencia archivístico: retos y oportunidades. Revista Española de Documentación Científica, 24(2), p. 178-197.

CASALET, Mónica, 1998. Tecnologia: concepto, problemas y perspectivas. Madrid: Siglo XXI.

CERDÁ DÍAZ, Julio, 2002. Desarrollo de sistemas de acceso on line a fondos de archivo. Propuesta metodológica. Bibliociencias. Disponible en:http://www.bibliociencias.cu/gsdl/collect/eventos/index/assoc/HASH3 820.dir/doc.pdf 
CORRALES, Isabel Medrano; SAMANIEGO, Luis Suárez, 2005. Gestión de archivos particulares en la era digital. El profesional de la información, 14(6), p. 442.

CRESPO, Arturo; GARCIA-MOLINA, Hector, 2001. Cost-driven design for archival repositories. EnProceedings of the 1st ACM/IEEE-CS joint conference on Digital libraries. ACM, p. 363-372.

CRUZ MUNDET, José Ramón, 2011. Diccionario de archivística. Madrid: Alianza Editorial.

CRUZ MUNDET, José Ramón; DÍEZ CARRERA, Carmen, 2015. El cálculo de costes de la preservación digital: un análisis de modelos. Anales de documentación, $\quad \mathbf{1 8}(2), \quad$ pp. $1-12 \quad$.DOI: http://dx.doi.org/10.6018/analesdoc.18.2.228411

DE ACUÑA, María José; AGENJO, Xavier, 2005. Archivos en la era digital: problema (y solución) de los recursos electrónicos. El profesional de la información, 14(6), p. 407-413. Disponible en: http://www.elprofesionaldelainformacion.com/contenidos/2005/noviembr e/2.pdf

DIGITAL RECORDS PRESERVATION: WHERE TO START GUIDE. ISO 2010. TC 46/SC 11/WG 7 - grupo de trabajo ISO responsable de Digital Records Preservation. Disponible en. http://www.niso.org/apps/group public/download.php/7273/Digital\%20r ecords $\% 20$ preservation $\% 20-\% 20$ Where $\% 20$ to $\% 20$ start $\% 20$ guide $\% 20$ $\% 20$ EN.pdf

DIRECTRICES PARA LA PRESERV ACIÓN DEL PATRIMONIO DIGITAL, 2003. París: UNESCO.[Consultada: 15-05-2017] Disponible en: http://unesdoc.unesco.org/images/0013/001300/130071s.pdf

ESTEBAN NAVARRO, Miguel Ángel, 2001. Los archivos de documentos electrónicos. El profesional de la información, 10(12), p. 41-45. Disponible en: http://elprofesionaldelainformacion.com/contenidos/2001/diciembre/9.pd $\underline{\mathrm{f}}$

GARCÍA-DELGADO, Purificación, 2004. El servicio de referencia digital. El profesional de la información, 12(4), p. 320-330. Disponible en: http://elprofesionaldelainformacion.com/contenidos/2003/julio/11.pdf

GIL VICENT, Vicent, 1997. La automatización de archivos municipales. Métodos de información, 4(17-18), p. 65-70. Disponible en: http://www.metodosdeinformacion.es/mei/index.php/mei/article/view/21 $\underline{4 / 236}$

HEREDIA HERRERA, Antonia, 2011. Lenguaje y vocabulario archivísticos. Algo más que un diccionario. Sevilla: Andalucia. Consejeria de Cultura. 
HERRERA-MORILLAS, José-Luis, 2002. Páginas web sobre exposiciones virtuales de fondo antiguo: recopilación y análisis. El profesional de la información, 11(2), p. 121-136. Disponible en: http://www.elprofesionaldelainformacion.com/contenidos/2002/marzo/5. pdf

IFLA, ICA, 2005. Directrices para proyectos de digitalización de colecciones y fondos de dominio público, en particular para aquellos custodiados en bibliotecas y archivos. Disponible en: https://www.ifla.org/files/assets/preservation-andconservation/publications/digitization-projects-guidelines-es.pdf

JAÉN GARCÍA, L. F, 2006. La Difusión de Archivos: estrategias para su proyección. Convención Internacional de Archivistas. Mar del Plata, Argentina.

LANKES, R. David; COLLINS III, John W.; KASOWITZ, Abby S., 2000. Digital Reference Service in the New Millennium: Planning, Management, and Evaluation. (The New Library Series, 6). Neal-Schuman Publishers, Inc., 100 Varick St., New York, NY 10013.

MARCOS, Mari Carmen, 1999. Los archivos en la era digital. El Profesional de la Información, $\quad \mathbf{8}(6), \quad$ p. $4-13 . \quad$ Disponible en: http://www.elprofesionaldelainformacion.com/contenidos/1999/junio/los archivos en la era digital.html

SÁNCHEZ REMÓN, Dinorah, 2003. El servicio de referencia virtual en la gestión de información. Acimed, ,11(2), p. 7-8. Disponible en: http://scielo.sld.cu/scielo.php?script $=$ sci arttext\&pid $=\mathrm{S} 1024-$ $\underline{94352003000200004}$

STOLTERMAN, Erik; CROON, Anna, 2004. Information Technology and the Good Life. Information systems research: relevant theory and informed practice, p. 689. Disponibleen:

http://www8.informatik.umu.se/ acroon/Publikationer $\% 20$ Anna/Stolterm an.pdf

ULLDEMOLINS, Álvaro, 2013. Recorridosvirtuales. Barcelona: Fundación para la Universidad Oberta de Catalunya. Disponibleen :https://www.exabyteinformatica.com/uoc/Informatica/Animacion 3D/A nimacion 3D (Modulo 5).pdf 